MEXАНIKA

MECHANICS

https://doi.org/10.15407/dopovidi2021.06.045

UDC 532.595

O.E. Lagodzinskyi ${ }^{1}$,

A.N. Timokha ${ }^{1,2}$, https://orcid.org/0000-0002-6750-4727

${ }^{1}$ Institute of Mathematics of the NAS of Ukraine, Kyiv

${ }^{2}$ Centre of Excellence "Autonomous Marine Operations and Systems", Department of Marine Technology,

Norwegian University of Science and Technology, Trondheim, Norway

E-mails: lagodzinskyi@gmail.com; tim@imath.kiev.ua, atimokha@gmail.com

\title{
Counter- and co-directed swirling-type waves due to orbital excitations of a square-base tank
}

Presented by Academician of the NAS of Ukraine A.N. Timokha

The analytic technique and numerical experiments are employed to show that the orbital elliptic translational excitations of a square-base container can, depending on the ratio of the semiaxes of the elliptic orbit, lead, when the forcing frequency is close to the lowest natural sloshing frequency, to both the counter- and co-directed (relative to the orbital forcing direction) stable swirling-type steady-state resonant waves. For a non-zero damping in the hydrodynamic wavy system, the passage to circular orbits makes the stable counter-directed swirling impossible.

Keywords: sloshing, swirling, stability, orbital forcing

In the recent paper [1], the authors have finalized a series of systematic theoretical studies on the steady-state resonant sloshing in a square-base tank, which performs a periodic (cyclic) motion with five degrees of freedom (sway, pitch, surge, roll, and yaw, when no vertical excitations are allowed) with the forcing frequency close to the lowest natural sloshing frequency. The Narimanov--Moiseev-type nonlinear modal system [2, Chapter 9] is employed. These studies established an asymptotic equivalence between periodic solutions of the nonlinear modal system (these solutions are associated with steady-state resonant surface waves) for an arbitrary cyclic nonparametric sway-pitch-surge-roll-and-yaw excitation and those ones coming from the modal system, when the tank performs an elliptic horizontal orbital motion. The equivalence implies that, for any periodic non-parametric (non-heave) tank excitation, one can match a horizontal elliptic tank orbit, which causes, to within the highest-order asymptotic quantities in the corresponding periodic solutions of the modal system, the same steady-state surface waves. Furthermore, the authors were concentrating on effective frequency domains of the almost standing and swirling steady-state wave modes for translational, diagonal, and oblique positions of the matched elliptic

Ци т в в нн я: Lagodzinskyi O.E., Timokha A.N. Counter- and co-directed swirling-type waves due to orbital excitations of a square-base tank. Допов. Наи. акад. наук Укр. 2021. № 6. С. 45-51.

https://doi.org/10.15407/dopovidi2021.06.045 


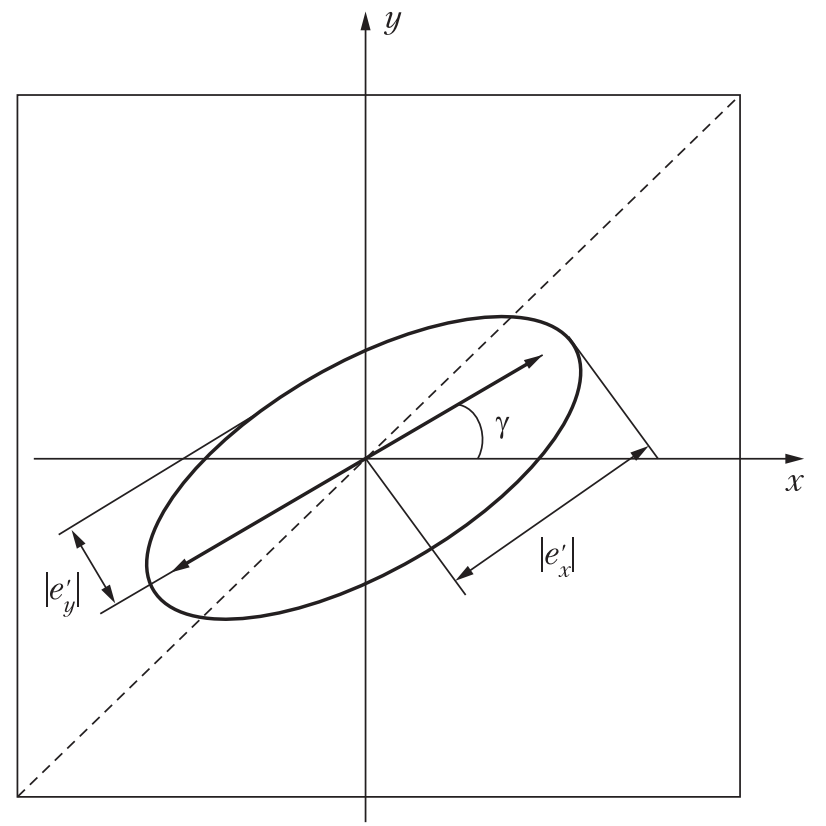

Fig. 1. A top view on a schematic elliptic orbital trajectory, which is characterized by the non-dimensional sizes of semiaxes $\left|e_{x}^{\prime}\right|$ and $\left|e_{y}^{\prime}\right|$, as well as the angle $\gamma$ between the major semi- and horizontalcoordinate axes. Because of the symmetry of two coordinate-planes, one can, without loss of generality, assume $0 \leqslant \gamma \leqslant \pi / 4$. The cyclic tank motions along the elliptic orbit occur either counterclockwise or clockwise so that, when the two translational generalized coordinates in (1) determine an elliptic orbit with a non-zero $e_{x}^{\prime} \leqslant 0, \quad 0 \leqslant\left|e_{y}^{\prime}\right| \leqslant\left|e_{x}^{\prime}\right|$, the forcing direction is defined from (2). The resonant swirling wave may be counter- or co-directed with respect to the orbital forcing direction.

orbits. These steady-state wave results were compared with those for an upright circular cylindrical tank [3-6] for which the longitudinal horizontal forcing [3] leads to standing, swirling and irregular wave modes, circular horizontal tank orbit $[4,5]$ yields the co-directed (to the orbit direction) swirling, and the elliptic tank excitation may cause both counter- and co-directed swirling-type waves [6]. The square-base cross-section makes the mentioned 'classification' of the steady-state resonant wave modes much more complicated, so that, e.g., stable nearly-standing waves become possible even for circular orbits, while, as we remember, this excitation type of circular-base tank only yields the co-directed swirling. A very special question appears on whether the counter-directed stable swirling wave mode exists, when the excitation orbit of a squarebase tank approaches the circular shape. The present paper addresses the question after conducting a parametric analytic-and-numerical analysis following the paper [1].

A square-base container moves translatorily along a horizontal elliptic orbit, as it is schematically shown in Fig. 1. For the prescribed elliptic semiaxes values $\left|e_{x}^{\prime}\right|$ and $\left|e_{y}^{\prime}\right|$ and the angle $\gamma$ between the major semiaxis and the horizontal coordinate axis, the two non-dimensional generalized coordinates describing the horizontal translational orbital tank motion can be defined to within the time-lag substitution $t=t+$ const as follows:

$$
\left\{\begin{array}{l}
\eta_{x}(t)=\eta_{1}(t)=\left[e_{x}^{\prime} \cos \gamma\right] \cos \sigma t-\left[e_{y}^{\prime} \sin \gamma\right] \sin \sigma t \\
\eta_{y}(t)=\eta_{2}(t)=\left[e_{x}^{\prime} \sin \gamma\right] \cos \sigma t+\left[e_{y}^{\prime} \cos \sigma\right] \sin \sigma t
\end{array}\right.
$$

Because of the symmetry planes $O x z$ and $O y z$ for the square base, one can, without loss of generality, assume $0 \leqslant \gamma \leqslant \pi / 4$ and associate the major semiaxis with $\left|e_{x}^{\prime}\right|$. Mathematically, the two generalized coordinates (1) determine either counterclockwise or clockwise orbit or imply a reciprocating tank excitation. For $0 \leqslant \gamma \leqslant \pi / 4$, the sign of $e_{x}^{\prime} e_{y}^{\prime}$ discriminates the counterclockwise $\left(e_{x}^{\prime} e_{y}^{\prime}>0\right)$ or clockwise $\left(e_{x}^{\prime} e_{y}^{\prime}<0\right)$ forcing, or the reciprocation 
$\left(e_{x}^{\prime} e_{y}^{\prime}=0\right)$

The forcing amplitude should be an asymptotically small value, which means that $\eta_{i}(t) \sim O(\varepsilon) \ll 1, i=1,2$.

The Narimanov--Moiseev asymptotic approximation of the free-surface resonant waves suggests the following ansatz:

$$
\begin{aligned}
& z=f(x, y, t)=\underbrace{a_{1}(t) f_{1}^{(1)}(x)+b_{1}(t) f_{1}^{(2)}(y)}_{O\left(\epsilon^{1 / 3}\right)}+\underbrace{a_{2}(t) f_{2}^{(1)}(x)+b_{2}(t) f_{2}^{(2)}(y)+c_{1}(t) f_{1}^{(1)}(x) f_{1}^{(2)}(y)}_{O\left(\epsilon^{2 / 3}\right)} \\
& +\underbrace{a_{3}(t) f_{3}^{(1)}(x)+b_{3}(t) f_{3}^{(2)}(y)+c_{21}(t) f_{2}^{(1)}(x) f_{1}^{(2)}(y)+c_{12}(t) f_{1}^{(1)}(x) f_{2}^{(2)}(y)}_{O(\epsilon)}+[\text { lin. }]+o(\epsilon),
\end{aligned}
$$

where $\left[f_{i}^{(1)}(x) f_{j}^{(2)}(y)\right]$ are the natural sloshing modes in the non-dimensional tank (scaled by the tank width), the term [lin.] implies the linear wave component, and

$$
f_{i}^{(1)}(x)=\cos (\pi i(x+1 / 2)) ; \quad f_{i}^{(2)}(y)=\cos (\pi i(y+1 / 2)), i \geqslant 0 .
$$

Based on the modal approximation (3), (4), the Narimanov--Moiseev-type modal system of nonlinear differential equations was derived [2, Chapter 9], which couples the sloshing-related generalized coordinates, $a_{1}(t), b_{1}(t), a_{2}(t), b_{2}(t), c_{1}(t), a_{3}(t), b_{3}(t), c_{21}(t), c_{12}(t)$. This system is studied in [1] for the arbitrary orbital tank forcing (1). The steady-state asymptotic (periodic) solution of the modal system contains the dominant asymptotic component

$$
a_{1}(t)=a \cos \sigma t+\bar{a} \sin \sigma t+O(\varepsilon) ; \quad b_{1}(t)=\bar{b} \cos \sigma t+b \sin \sigma t+O(\varepsilon), a \sim b \sim \bar{a} \sim \bar{b} \sim O\left(\varepsilon^{1 / 3}\right),
$$

where $\sigma$ is the forcing frequency, and the non-dimensional amplitude parameters $a, \bar{a}, b, \bar{b}$ are real solutions of the following system of nonlinear algebraic (secular) equations:

$$
\left\{\begin{array}{l}
a\left[\Lambda+m_{1}\left(a^{2}+\bar{a}^{2}\right)+m_{2} \bar{b}^{2}+m_{3} b^{2}\right]+\bar{a}\left[\left(m_{2}-m_{3}\right) \bar{b} b+\xi\right]=P_{1} e_{x}^{\prime} \cos \gamma \\
\bar{a}\left[\Lambda+m_{1}\left(a^{2}+\bar{a}^{2}\right)+m_{2} b^{2}+m_{3} \bar{b}^{2}\right]+a\left[\left(m_{2}-m_{3}\right) \bar{b} b-\xi\right]=-P_{1} e_{y}^{\prime} \sin \gamma \\
b\left[\Lambda+m_{1}\left(b^{2}+\bar{b}^{2}\right)+m_{2} \bar{a}^{2}+m_{3} a^{2}\right]+\bar{b}\left[\left(m_{2}-m_{3}\right) \bar{a} a-\xi\right]=P_{1} e_{y}^{\prime} \cos \gamma \\
\bar{b}\left[\Lambda+m_{1}\left(b^{2}+\bar{b}^{2}\right)+m_{2} a^{2}+m_{3} \bar{a}^{2}\right]+b\left[\left(m_{2}-m_{3}\right) \bar{a} a+\xi\right]=P_{1} e_{x}^{\prime} \sin \gamma
\end{array}\right.
$$

in which the so-called Moiseev detuning parameter

$$
\Lambda=1-\sigma_{1}^{2} / \sigma^{2}=O\left(\varepsilon^{2 / 3}\right)
$$

depends on the forcing frequency (the smallness of $\Lambda$ on the $O(\varepsilon)$-scale reflects the resonance condition, i.e. it says that the forcing frequency $\sigma$ should be close to the lowest natural sloshing frequency $\left.\sigma_{1}\right)$, the relatively small damping coefficient $\xi=2 \xi_{0,1}=2 \xi_{1,0}=O\left(\varepsilon^{2 / 3}\right)$ is associated with the logarithmic decrement of the lowest natural sloshing modes $\left[f_{1}^{(1)}(x)\right]$ and $\left[f_{1}^{(2)}(y)\right]$, but $m_{1}, m_{2}$ and $m_{3}$, as well as $P_{1}$, are functions of the non-dimensional liquid depth $h$. Explicit 
formulas for $P_{1}, m_{1}, m_{2}, m_{3}$ and $\xi$ can be found in [1], but [2, Fig. 9.7] graphically illustrates the values of $m_{1}, m_{2}$ and $m_{3}$ as functions of $h$, specifically,

$$
m_{2}<m_{1}<0,0<m_{3}, m_{1}+m_{3}>0 \quad \text { as } \quad h>0.3368 \ldots
$$

In the most general case, computing the non-dimensional amplitude parameters $a, \bar{a}, b, \bar{b}$ from the secularity equations (6) for each given frequency $\sigma$ [solution of (6) may not be unique] and substituting the result into (5) and (3) determine the lowest-order approximation of resonant steady-state surface-wave patterns (modes), which can be either stable or unstable. An analytic stability criterion is derived and proven in [7, Eq. (4.10)].

The stable steady-state wave solutions of the Narimanov-Moiseev-type modal equations describe swirling (rotary), standing, or/and nearly-standing waves. When all steady-state solutions for the fixed forcing frequency $\sigma$ are unstable, irregular (chaotic) surface wave patterns are theoretically expected. In the lowest-order approximation (using only the $O\left(\varepsilon^{1 / 3}\right)$-order terms in (3)), one can discriminate the following stable wave types as functions of the amplitude parameter $\Xi=a b+\bar{a} \bar{b}$ :

$O\left(\varepsilon^{2 / 3}\right)=\Xi>0$-counterclockwise swirling; $O\left(\varepsilon^{2 / 3}\right)=\Xi<0$ - clockwise swirling

$$
O(\varepsilon)=\Xi \text { - nearly standing wave; } o(\varepsilon)=\Xi \text { - standing wave. }
$$

When taking $P_{1}, m_{1}, m_{2}, m_{3}$ and $\xi$ from [1] and/or [2] for a fixed non-dimensional liquid depth $h$, as well as the elliptic forcing parameters, which include $e_{x}^{\prime}, e_{y}^{\prime}$, and $\gamma$, and varying $\Lambda$ by (7) in (6), the solution of the secular system (6) with respect to the non-dimensional amplitude parameters $a, \bar{a}, b, \bar{b}$ makes it possible to draw the wave-amplitude response curves in the $\left(\sigma / \sigma_{1}, A, B\right)$-space, where the resulting $O\left(\varepsilon^{1 / 3}\right)$-order non-dimensional amplitudes in the horizontal directions (along $O x$ and $O y$ ) are

$$
A=\sqrt{a^{2}+\bar{a}^{2}}, \quad B=\sqrt{\bar{b}^{2}+b^{2}} .
$$

Implementing the stability criterion [7, Eq. (4.10)] identifies for every point on the response curves whether it corresponds to stable or unstable solution (steady-state wave).

The limiting (longitudinal and diagonal) forcing cases with $\gamma=0$ and $\gamma=\pi / 4$ are investigated in [2, Chapter 9] in an analytic way. For these cases, it was proved in [1] that both counter- and co-directed stable swirlings exist, when $e_{y}^{\prime} / e_{x}^{\prime}=\delta_{1}=0$ (the reciprocating tank motion), but counter-directed resonant steady-state swirling disappears as $\left|\delta_{1}\right| \rightarrow 1$ (the circular tank orbit). Specifically, the developed analytic technique is not applicable to oblique positions of the elliptic tank orbit, i.e., when $0<\gamma<\pi / 4$. That is why, the oblique elliptic forcing is only exemplified in [1] with $\gamma=\pi / 6$ and $\gamma=\pi / 12$, and other input parameters associated with experiments in [8].

Utilizing a modified semianalytic algorithm from [1], we conducted an exhaustive numerical analysis of response curves in the $\left(\sigma / \sigma_{1}, A, B\right)$-space for $0<\gamma<\pi / 4,0.4 \leqslant h \leqslant 0.8$ (the response curves practically do not change with larger liquid depths), $0.001 \leqslant\left|e_{x}^{\prime}\right| \leqslant 0.01,0<\delta_{1}<1$, and $0.001 \leqslant \xi \leqslant 0.01$. The input values belong/cover the most realistic and physically admissible domains. Even though the response curves may significantly change with the chosen input values, 

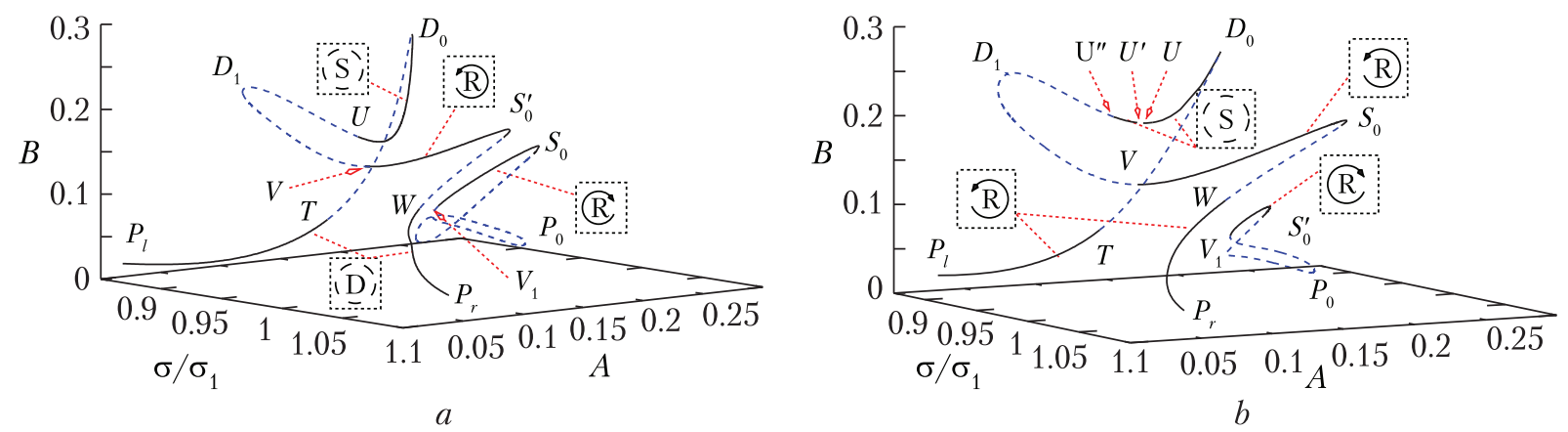

Fig. 2. The wave amplitude response curves in the $\left(\sigma / \sigma_{1}, A, B\right)$-space computed and drawn for $h=0.6$, $\left|e_{x}^{\prime}\right|=0.00727, \xi=0.0256$, and $\gamma=2 \pi / 9$. Panel $(a)$ corresponds to the case $\delta_{1}=0.0$, but $(b)$ is drawn with $\delta_{1}=0.2$ (the counterclockwise elliptic orbital forcing with the nearly diagonal position of the elliptic orbit). The solid lines mark the stable solutions, but the dashed lines imply the instability. There are two branches, $P_{l} T D_{0} U\left(U^{\prime} U^{\prime \prime}\right) D_{1} V S_{0} W P_{r}$ and $V_{1} S_{0}^{\prime} P_{0}$ (loop-type), for the panels. The two subbranches $V S_{0}$ and $V_{1} S_{0}^{\prime}$ are associated with the co- and counter-directed (counterclockwise and clockwise swirling waves), respectively. The subbranches $P_{l} T$ and $W P_{r}$ change from the standing (nearly diagonal, 'D') to the nearly-standing ('S') and, further, to the counterclockwise swirling ('R') as $\left|\delta_{1}\right|$ increases. When the forcing frequencies belong to the range $T V$, there is no stable steady-state sloshing, and, therefore, irregular (chaotic) wave motions are expected.
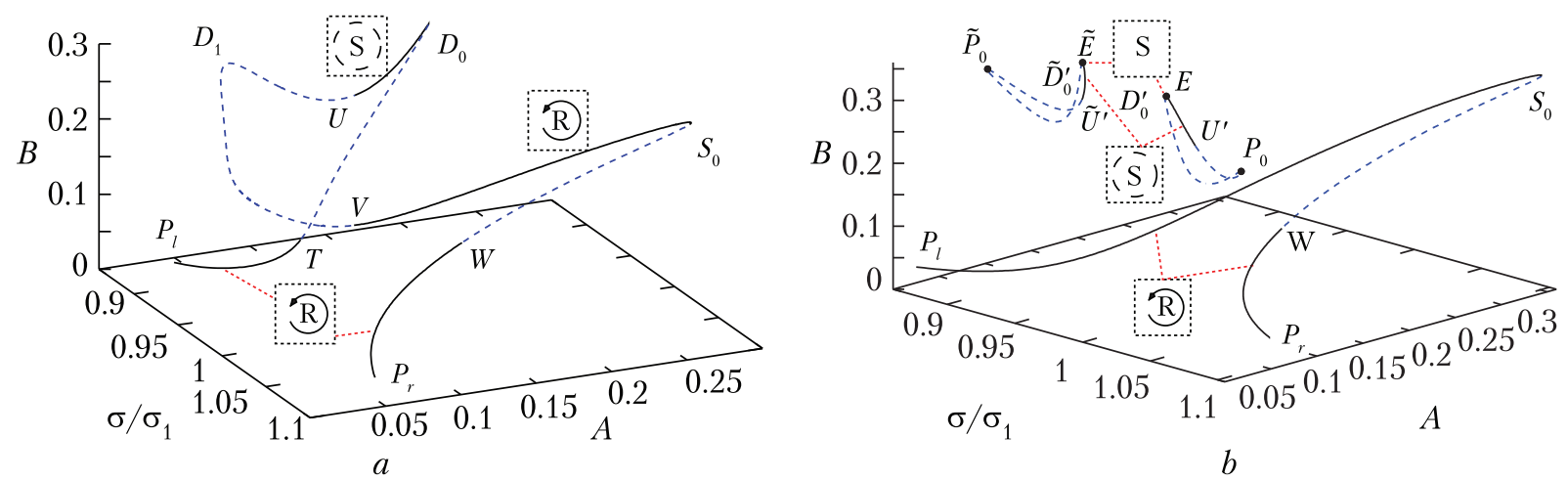

Fig. 3. The same as in Fig. 2 but with the ratio of semiaxes of the elliptic orbit $\delta_{1}=0.6$ [panel $(a)$ ] and $\delta_{1}=1$ (the circular counter-directed forcing [panel $(b)]$. For these ratios, the loop-type branch $V_{1} S_{0}^{\prime} P_{0}$ on which the stable counter-directed swirling was detected in Fig. 2, disappears. Specifically, the stable co-directed swirling is associated with points of the subbranches $P_{l} T, V S_{0}$, and $W P_{r}$. The subbranch $D_{0} U$ continues implying the stable nearly standing wave mode.

globally, all of them confirm that the counter-directed swirling mode becomes impossible (disappears), as $\left|\delta_{1}\right| \rightarrow 1$.

Normally, the counter-directed swirling exists, as $\left|\delta_{1}\right|<0.2$. This fact is illustrated in Fig. 2 for $h=0.6,\left|e_{x}^{\prime}\right|=0.00727, \xi=0.0256$, and $\gamma=2 \pi / 9$, which correspond to the experimental input data in [8]. Case (a) implies the reciprocating oblique tank motion $\left(\left(\delta_{1}=0.0\right)\right.$ but panel (b) depicts the response curves for the counterclockwise elliptic oblique forcing with $\delta_{1}=0.2$. In these both cases, the oblique forcing is nearly diagonal. The solid lines correspond to stable solutions (sloshing), whereas the dashed lines imply the instability. One can see the two continuous branches, $P_{l} T D_{0} U\left(U^{\prime} U^{\prime \prime}\right) D_{1} V S_{0} W P_{r}$ and $V_{1} S_{0}^{\prime} P_{0}$ (loop-type) on which the stable swirling is pre- 
sented by the subbranches $V S_{0}$ (the co-directed resonance swirling for the counterclockwise forcing) and $V_{1} S_{0}^{\prime}$ (the counter-directed [clockwise] swirling). The both subbranches appear in a neighborhood of the primary resonance, i.e., around $\sigma / \sigma_{1}=1$. The subbranches $P_{l} T$ and $W P_{r}$ change from the standing (nearly diagonal, 'D') to the nearly-standing (S) and, further, to the counterclockwise swirling (R), as $\left|\delta_{1}\right|$ increases. Comparing $(a)$ and $(b)$ demonstrates that the zone of the counter-directed (clockwise) swirling increases with $\left|\delta_{1}\right|$.

For all the tested input parameters, the counter-directed (clockwise for the studied case) swirling wave mode normally disappears, as $0.6 \leqslant\left|\delta_{1}\right|$. This fact is illustrated in Fig. 3, which is drawn with the same input parameters as in Fig. 2, but for $\delta_{1}=0.6$ [panel $(a)$ ] and $\delta_{1}=1$ (the circular counterclockwise forcing [panel $(b)$ ]. The branching in panel $(a)$ is characterized by the unique continuous curve $P_{l} T D_{0} U D_{1} V S_{0} W P_{r}$ where the stable co-directed (counterclockwise) swirling is associated with $P_{l} T, V S_{0}$, and $W P_{r}$. The subbranch $D_{0} U$ keeps implying the stable nearly standing wave mode. When the ratio of semiaxes approaches 1, the subbranch $D_{0} U$ splits into the two loop-type branches. Fig. $3(b)$ illustrates them for the given input parameters.

Conclusions. The exhaustive numerical analysis of response curves, which correspond to the steady-state waves due to the elliptic orbital oblique forcing, shows for the finite non-dimensional liquid depth $0.4 \leqslant h$ that the horizontal orbital elliptic forcing may cause both the co- and counter-directed stable steady-state swirling wave regimes for smaller ratios of semiaxes of the ellipse, but only the stable co-directed swirling exists, when the elliptic shape tends to the circle.

The authors acknowledge the financial support of the National Research Foundation of Ukraine (Project number 2020.02/0089). The second author also acknowledges a partial support of Centre of Autonomous Marine Operations and Systems (AMOS) whose main sponsor is the Norwegian Research Council (Project number 223254-AMOS).

\section{REFERENCES}

1. Faltinsen, O. M., Lagodzinskyi, O. E. \& Timokha, A. N. (2020). Resonant three-dimensional nonlinear sloshing in a square base basin. Part 5. Three-dimensional non-parametric tank forcing. J. Fluid Mech., 894, A10, pp. 1-42. https://doi.org/10.1017/jfm.2020.253

2. Faltisen, O. M. \& Timokha, A. N. (2009). Sloshing. Cambridge Univ. Press.

3. Royon-Lebeaud, A., Hopfinger, E. J. \& Cartellier, A. (2007). Liquid sloshing and wave breaking in circular and square-base cylindrical containers. J. Fluid Mech., 577, 25, pp. 467-494.

https://doi.org/10.1017/S0022112007004764

4. Horstmann, G. M., Herremann, W. \& Weier, T. (2020). Linear damped interfacial wave theory for an orbitally shaken upright circular cylinder. J. Fluid Mech., 891, A22, pp. 1-38. https://doi.org/10.1017/jfm.2020.163

5. Raynovskyy, I. \& Timokha, A. (2018). Steady-state resonant sloshing in an upright cylindrical container performing a circular orbital motion. Math. Probl. Eng., 2018, Art. 5487178, pp. 1-8. https://doi.org/10.1155/2018/5487178

6. Raynovskyy, I. A. \& Timokha, A. N. (2018). Damped steady-state resonant sloshing in a circular container. Fluid Dyn. Res., 50, Art. 045502, pp. 1-20. https://doi.org/10.1088/1873-7005/aabe0e

7. Faltisen, O. M. \& Timokha, A. N. (2017). Resonant three-dimensional nonlinear sloshing in a square-base basin. Part 4. Oblique forcing and linear viscous damping. J. Fluid Mech., 822, pp. 139-169.

https://doi.org/10.1017/jfm.2017.263

8. Ikeda, T., Ibrahim, R. A., Harata, Y. \& Kuriyama, T. (2012). Nonlinear liquid sloshing in a square tank subjected to obliquely horizontal excitation. J. Fluid Mech., 700, pp. 304-328.

https://doi.org/10.1017/jfm.2012.133

Received 08.08.2021 
О.Е. Лагодзинський 1

O.M. Tuмоха ${ }^{1,2}$, https://orcid.org/0000-0002-6750-4727

${ }^{1}$ Інститут математики НАН України, Київ

2 Центр досконалості «Автономні морські операції та системи»,

Департамент морських технологій, Норвезький університет природничих та технічних наук,

Трондхейм, Норвегія

E-mails: lagodzinskyi@gmail.com; tim@imath.kiev.ua, atimokha@gmail.com

ПРОТИ- ТА СПІВНАПРАВЛЕНІ КРУГОВІ ХВИЛІ

ЗА ОРБІТАЛЬНИХ ЗБУРЕННЯХ БАКУ КВАДРАТНОГО ПЕРЕРІЗУ

Застосовується аналітична техніка та чисельні експерименти для того, аби показати, що орбітальні еліптичні поступальні збурення баку квадратного перерізу можуть призвести в залежності від співвідношення напіввісей еліптичної орбіти до як проти- так і співнаправленої (відносно напрямку збурення баку) стійкої усталеної кругової хвилі. Частоти збурення близькі до першої власної частоти коливання рідини. Для ненульового демпфування в гідродинамічній системі перехід до кругових орбіт робить неможливими протинаправлені кругові хвилі.

Ключові слова: хлюпання рідини, кругова хвиля, стійкість, орбітальне збурення. 